\title{
'...EVEN ACCOUNTANTS DON'T DREAM IN POWERPOINTS AND T-ACCOUNTS' REPORT FROM THE INAUGURAL IRISH ACCOUNTING AND FINANCE ASSOCIATION LEARNING AND TEACHING DAY
}

\author{
Margaret Healy \\ University College Cork \\ Elaine Doyle \\ University of Limerick \\ Hugh McBride \\ Galway-Mayo Institute of Technology \\ Patrick Buckley \\ University of Limerick \\ Michael Farrell \\ University College Cork
}

While teaching and learning in accounting have always been demanding endeavours, the millennial and the Gen $\mathrm{Z}$ generations pose particularly significant pedagogic challenges in terms of how they acquire and process knowledge (see, for example, Daly, Reid, Buckley and Doyle, 2016). New technological developments have led to an abundance of information at students' fingertips with rapid access to data available. Teaching students to process this data into knowledge is an important challenge. There has been a substantial shift from generating and assessing information to being able to differentiate the varying quality of information and analysing it. Passive learning has festered within this generation, with immediate access to comprehensive study notes, lecture slides, solutions to tutorial questions, articles, past exams and so on, fostering a feeling of apathy with respect to the educational experience. This is exacerbated by increasing class sizes (over 500 students in a lecture is not uncommon), leading to feelings of isolation and disconnection within the learning community. Business schools have seen a significant increase in the number of non-traditional learners registering on full-time programmes or demanding access to part-time or distance learning offerings. Diverse student 
Healy et al.

cohorts encompassing traditional undergraduate students, mature students with disparate levels of experience, and students whose first language is not English also present challenges for higher education teachers.

Future accounting graduates must not only be technically excellent, but must also have the ability and confidence to question the status quo, critically evaluate alternatives, morally unreproachable, work effectively as part of a team and be open enough to respond to and embrace change (Doyle, Buckley and Carroll, 2013). Contemporary accounting teaching must, therefore, create the classroom environment to generate enquiry by constantly challenging and stimulating students. Educators must strive towards generating deep, active and reflective learning experiences that engage this new generation, developing learning platforms that encourage interaction and blend with students' new learning styles.

Within this broad context, on Friday 29 November 2019, the Irish Accounting and Finance Association (IAFA) ran its inaugural Learning and Teaching Day at Chartered Accountants House, Dublin. The day opened with a keynote presentation, followed by shorter presentations demonstrating specific teaching innovations, and concluded with a series of individual participant workshops based on participantdriven themes.

The opening plenary by Professor Martin Valcke addressed the issue of motivation, in particular motivation of students in higher education, as a mediating variable to student engagement. Describing motivation as being cognitive and dependent both on subject matter and learning context, Professor Valcke emphasised the importance of creating a mental model linked to students' prior knowledge. In essence, lecturers need to first 'catch' and then 'hold' their students' attention and focus. Three established theories (interest theory, self-efficacy theory, and self-determination theory) were each considered and examples of their use in teaching practice provided. The key role for educator motivation as part of the learning context was also addressed. Professor Valcke cautioned participants about the importance of implementing changes at programme level rather that module level, and highlighted the importance of the fit with the evaluation systems and assessment practices and rewards of those same programmes.

Hugh McBride presented and described various techniques through which he fosters awareness of ethical concepts and considerations in the classroom. Ethical questions are multi-faceted, complex, messy, ambiguous and contentious - hence students are not always motivated to engage. Using a variety of prompts based on topical events, students are encouraged to try and fail, rather than failing to try, in this challenging and confusing space, engaging with the multiple valid but differing perspectives that ethical considerations raise. Hugh presented this in terms of facilitating students moving from confusions of understanding, to understandings of confusion, as the complexity of dealing with problems having 'no right answers' is grappled with. As a preparation for the rest of their ethics module, this approach engages students, builds their confidence and trust in the process, and identifies issues of concern to students for discussion later, thus acting as a learning mechanism for the lecturer as well as the students.

Dr Emer Mulligan and Dr Kim Key discussed the design and implementation of a tax project with students across two countries (Ireland and the United States). 
Focusing on a shared desire to reflect the reality of tax in practice for their students, the group-based project sought to increase students' awareness of ethical tax issues and understanding of international corporate tax planning opportunities and techniques - all whilst conducting group work with students in another country. The result was a culturally enriching experience for lecturers and students alike, with clear potential to provide insight into the complexity and challenge of ethical decision-making in taxation, whilst also enhancing students' cultural sensitivity. Originating as an unintended consequence of a random conversation at a taxation conference, their work has expanded into an action research project investigating an intercultural teaching exercise in the domain of international taxation.

Dr Patrick Buckley outlined the use of gamification as a pedagogical tool in the context of a large taxation module. Gamification involves using characteristics typically associated with games, such as leader boards, prizes, avatars and so on, in non-game contexts to mediate behaviour. It does not necessarily involve the use of an actual game or indeed information technology, but rather involves the integration of design elements or activity patterns traditionally found in games into educational contexts. Dr Buckley has used gamification techniques to motivate and engage students across a number of business modules. For the purposes of this session, Dr Buckley described a gamification project designed to engage students with the wider tax context by focusing attention on the Irish national budget. Students were required to make forecasts about what tax policy measures would be introduced in the national budget using a group decision-making tool called a prediction market. The approach used gamification techniques to encourage students to investigate the wider policy debates that inform the budget. Students were given virtual cash which they used to purchase shares in potential outcomes from the budget and could trade using these shares. The project was effective in motivating students; however, Dr Buckley noted that not everyone enjoys gamified learning, and that gamification needs to be used as part of suite of learning interventions to improve engagement and motivation.

Peter Weadock explored the teaching of accounting principles and practices to 'hybrid' business students in an arts college, through the use of storytelling. Building on the five essential elements of a story (characters, plot, setting, conflict and resolution), Peter described how a 'storytelling' approach helped students to move from the 'documenting of' to 'a documentary on' the contents and use of accounting reports. After all, as he stated, 'even accountants don't dream in PowerPoints and T-accounts!'

In the final formal presentation of the day, Dr Margaret Healy invited the participants to consider turning their teaching innovations into research outputs. Key considerations highlighted included: the need to re-articulate the 'teaching problem' as a 'research problem' from which a contribution to the extant education/ professional literature can then be made; the need to consider the specific problem from a wider lens (national/international applicability) rather than the more local focus underpinning the teaching innovation; and ethical considerations as the classroom becomes the research site.

Based on the above contributions, four themes for the afternoon workshop sessions were proposed and put to participants for roundtable discussion. These were: 
Healy et al.

- 'Catch and Hold' - When it doesn't add up? (how do we 'catch' students and 'hold' their attention in an accounting context)

- Whose Classroom Is It Anyway? (Sage on the stage or guide on the side?)

- Doing More with Less (Larger classes and more diversity with constrained resources)

- Us and Them: Relationships between Academic Bodies and Professional Accounting Institutions

Across three 15-minute 'workshop' style sessions, participants had opportunities to move between each of the four themes and to contribute to shaping and forming possible future teaching innovations; initiate conversations for future workshops and conferences; discover the experiences and concerns of others; and generally network with peers from other educational institutions and professional accountancy bodies.

Under the first theme, participants discussed various ways of 'catching' students' attention and 'holding' it. Numerous techniques were shared and various positives and negatives were debated. The idea of students taking responsibility for their own learning was emphasised. Educators and students need to be mindful that learning can be difficult and involves cognitive effort on the part of the student which cannot be carried by instructors. Neither students nor instructors should lose sight of this in the pursuit of quick fixes or using the latest technology for its own sake.

Ownership of the 'classroom' still presents as predominantly a space within which a quasi-unethical power imbalance between participants is (implicitly) enabled and enacted. Whilst recognising the broader possibilities of a 'classroom' determined less by spatial arrangements and more by students' sense of belonging in and engagement with learning activities, participants nonetheless had a variety of outstanding concerns:

- The normalising effect of early education (primary and secondary), creating expectations of spatial arrangements and (accepted) unequal agency

- Students' vulnerability and lack of knowledge when asked to 'take control' of the classroom, for example, in a flipped classroom setting

- The dangers of online/cloud-based classrooms: technology as a solution in search of a problem

In the context of 'doing more with less', participants discussed the numerous constraints under which contemporary teaching and learning in higher education takes place, including pressures on time and financial restrictions. More worrying perhaps are the increasing administrative burdens being imposed on teaching faculty due to evolving bureaucracy and accreditation demands. If you can't easily measure progress and achievement of learning outcomes in a standardised, evidence-based manner, it is increasingly difficult to justify trying a new teaching and learning innovation or to introduce new content into the curriculum. There was 
Report from the Inaugural IAFA Learning and Teaching Day

a sense, particularly across undergraduate programmes, that learners today have different needs and wider-ranging expectations, making it increasingly difficult to capture and retain their attention. Smaller class sizes, space within modules to cover a wider range of topics in more depth, work placements for students and the freedom to introduce more research into the curriculum were high on the wish list for most faculty members. Many lecturers consider communication and teamwork skills to be critical but lack the resources to properly facilitate student engagement with these skill-sets and evidence-based means of assessing them effectively. Using technology to optimum effect was considered critical in addressing some of these issues. Ensuring students have 'skin in the game' was also suggested as a means for engaging students, with approaches like co-creation and self-directed assignment being identified as relevant tools. Finally, many participants referenced the tension between the demand for hard technical skill development and the need for students to develop softer, transferable skills. There were calls for an open dialogue between all relevant stakeholders in the higher level system centred on the prioritisation and assessment of the range of skill needs for accounting students.

A fourth theme that emerged on the day was 'Us and Them: Relationships between Academic Bodies and Professional Accounting Institutions'. The focus of the discussion was on the influence of the professional accounting bodies on accounting degree programme curriculum design, delivery and assessment (on teaching and learning) in Higher Education Institutes (HEIs). In particular, whether HEIs are restricted adversely by the requirements of the professional bodies, and, if so, whether there was anything that could be done about it. There was general agreement that the requirements of the professional bodies have a significant influence on curriculum design, delivery and assessment in HEIs. This was considered beneficial to HEIs in promoting their programmes, but also restrictive in terms of the nature of undergraduate education. The availability of exemptions from the professional examinations is an important consideration for prospective students. As such, they are an important promotional tool for HEIs, enhancing their ability to attract students in a competitive market. They serve as an indicator of programme quality and comparability. In this regard, accreditation by professional bodies is of particular relevance in underpinning the credibility of the standard of the programmes offered by institutes of technology and private colleges. The high quality of the various professional syllabi was also acknowledged. This benefits HEIs in designing their programmes and modules by enabling academics to piggyback on the prior work of the professional bodies. Concern was expressed, however, that the focus of HEIs on obtaining and maintaining exemptions has skewed the academic curriculum excessively towards a narrow, technical education, including restricting the variety of assessment instruments used, and stifling experimentation and innovation in approaches to teaching and learning. There was general agreement that a broader-based undergraduate accounting education is desirable. This should incorporate an emphasis on understanding the business environment and conceptual frameworks, and on developing a more rounded graduate with a range of interpersonal and self-management skills, affective dispositions (in particular, critical thinking) and professional attributes. Such a broader-based accounting education is likely to become more relevant in the future, particularly in the context of the 
Healy et al.

challenges posed by the application of technology (including artificial intelligence) to aspects of the technical work of accountants. The difficulty for individual HEIs, however, is the risk of losing exemptions and of damaging the relative attractiveness of their particular programme in the short-term if they unilaterally redesign their curriculum to incorporate this broader perspective. In this context, it was suggested that there may be scope for the HEIs to collectively approach the professional bodies for a discussion around rethinking the undergraduate curriculum. Chartered Accountants Ireland in particular expressed an openness towards engaging in such an exercise.

Representatives from Chartered Accountants Ireland (CAI), Institute of Certified Public Accountants in Ireland (CPA Ireland), Chartered Institute of Management Accountants (CIMA) and Assocation of Chartered Certified Accountants (ACCA) all participated in this teaching and learning event, as well as lecturers from numerous HEIs (50 participants were involved over the course of the day). Feedback from the event was extremely positive, with attendees indicating that the content and format was useful and thought-provoking. In particular, the opportunity to interact with other educators and representatives of the various professional accountancy bodies was welcomed. Participants were anxious for this event to become part of the annual IAFA calender. IAFA would like to formally thank CAI for their hospitality and engagment in hosting this jointly beneficial event.

\section{COMPLETE LIST OF CONTRIBUTIONS}

- 'Motivational theories and their implications for classrooms in higher education' - Professor Martin Valcke, Ghent University, Belgium

- 'Fostering ethical awareness' - Hugh Mc Bride, GMIT

- 'Instilling intercultural intelligence ... how did it come to this' - Dr Margaret Healy, UCC, Kim Key, Auburn University, USA, Emer Mulligan, NUIG and Maeve McCutcheon, UCC

- 'Gamification: implementation and impacts' - Dr Patrick Buckley, UL

- 'What's the story Paciolli?' - Peter Weadock, IADT Dun Laoghaire

- 'Turning your teaching innovation into a publishable research output' - Dr Margaret Healy, UCC

\section{REFERENCES}

Daly, P., Reid, K., Buckley, P. and Doyle, E. (eds) (2016). Innovative Business Education Design for 21st Century Learning, Switzerland: Springer.

Doyle, E., Buckley, P. and Carroll, C. (eds) (2013). Innovative Business School Teaching: Engaging the Millennial Generation, New York, NY: Routledge. 